\title{
IN MEMORY OF ILYA PRIGOGINE
}

This special issue is devoted to the memory of the great scientist Ilya Prigogine, our teacher and friend.

Prigogine's fundamental contributions to nonequilibrium physics and complexity not only shaped the views of twentieth century science but also opened pathways for the twenty-first century research. The science of complexity emerged as a new paradigm and has caught the attention of numerous scientists all over the world in the last few decades. Prigogine led us to an understanding of the physical conditions underlying the emergence of complex structures and self organization. This is the law of order through fluctuations far from equilibrium. Already a Nobel Laureate, he was one of the first to understand and accept the extreme importance of this new field of studies. He proposed revolutionary ideas about discrete time, space, and the new laws of physics underlying self organization and the interdependence of complex systems. It is never easy to be the first and it is always extremely complicated to change the opinions and established views of scientists, especially in physics. However, he succeeded in doing so, and that is why we all appreciate and admire him. He had a unique scientific vision and intuition, which gave him the force to develop the understanding of issues such as deterministic chaos, discrete time and space, irreversibility and nonintegrability. Prigogine took special care to share his knowledge not only with his students and colleagues, but also with the general public. His scientific results and views have been formulated in brilliant papers and books. Until the very moment he passed away, Ilya Prigogine was working on finding new laws of physics, laws which will provide understanding of complex, living and thinking systems dynamics. It will take some time to understand his innovative ideas which up to now are finding scientific confirmation.

I. Prigogine always wanted things to run faster and understanding to be better and deeper. Each result made him more uneasy because he saw already many more questions appearing. He never gave up, even when facing problems in the understanding of his ideas.

To a great extent, the appearance of this journal owes itself to discussions with Professor Prigogine; from the beginning he served as Honorary Editor. 


\section{In memory of Ilya Prigogine}

The main aims of DDNS are the stimulation and promotion of new ideas related to the search of "first principles" for discrete chaotic dynamics of complex, living and thinking systems, the development of a "calculus of iterations" as a main mathematical tool for describing complex nonlinear phenomena, and the finding of links between natural and social sciences based on the new paradigm of systems complexity. Eight years of the journal's existence have confirmed the importance of these problems for investigations; there has been constantly growing interest which illustrated once again Ilya Prigogines's great vision of the science of the future.

We express our gratitude to all contributors to this special issue, to the scientists who were working and communicated with Ilya Prigogine. Their contributions are the best confirmation of the fact that the ideas generated in the scientific environment created by Ilya Prigogine are alive and developing. Future work will bring to life his visions about understanding complex, living and thinking systems dynamics, even if this will imply great changes in our present understanding of physics.

\author{
Ioannis Antoniou \\ International Solvay Institutes \\ of Physics and Chemistry, \\ Belgium
}

\author{
Vladimir Gontar \\ International Group for \\ Chaos Studies, \\ Israel
}




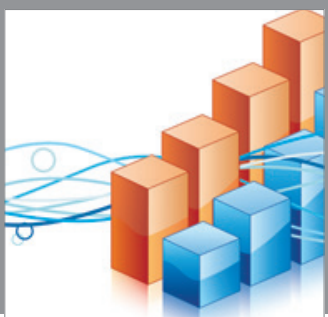

Advances in

Operations Research

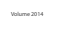

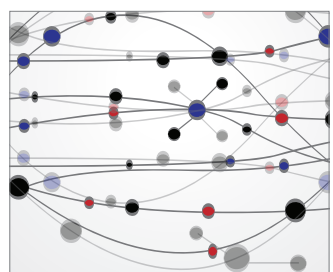

\section{The Scientific} World Journal
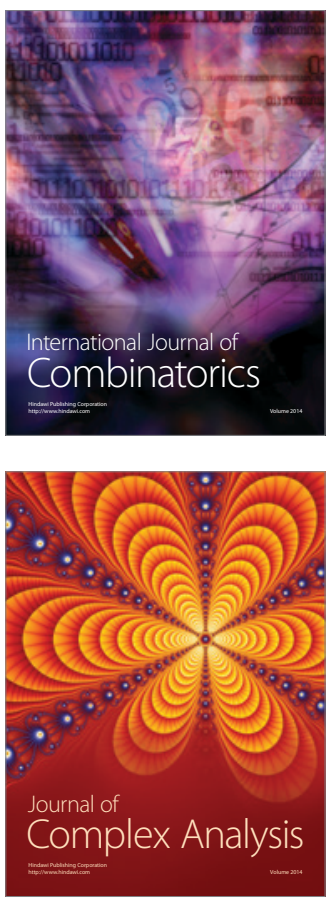

International Journal of

Mathematics and

Mathematical

Sciences
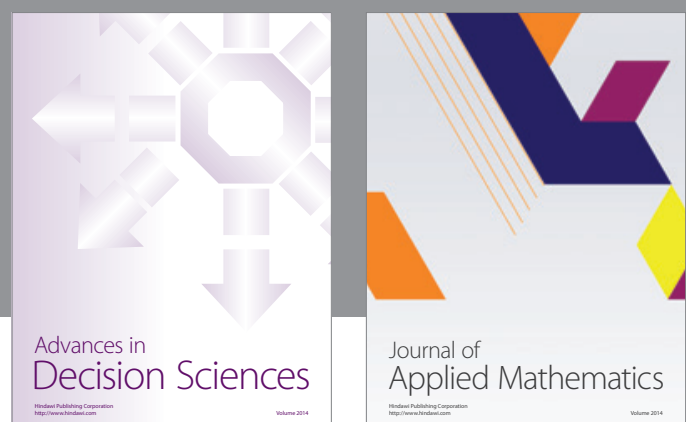

Journal of

Applied Mathematics
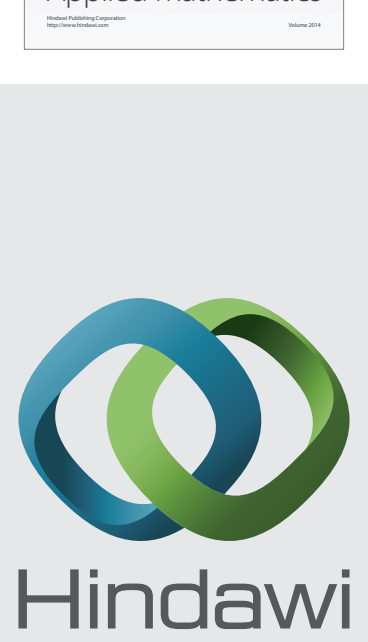

Submit your manuscripts at http://www.hindawi.com
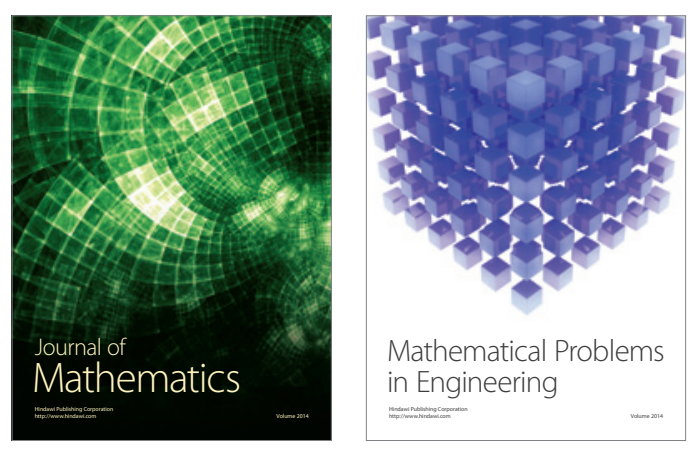

Mathematical Problems in Engineering
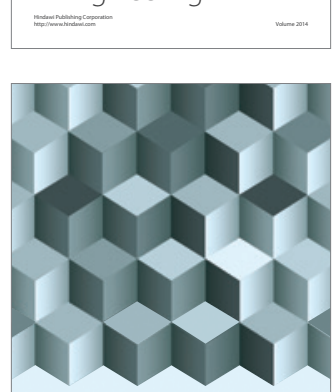

Journal of

Function Spaces
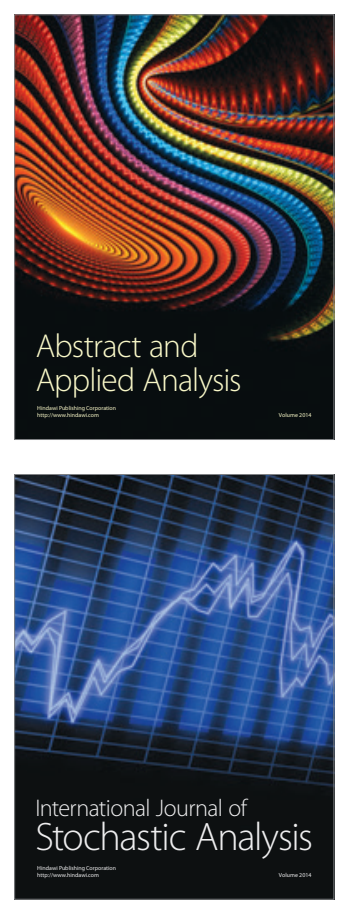

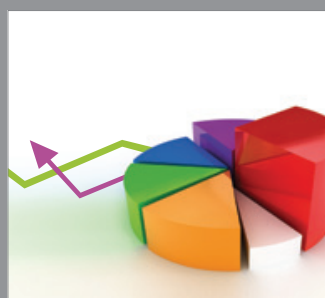

ournal of

Probability and Statistics

Promensencen
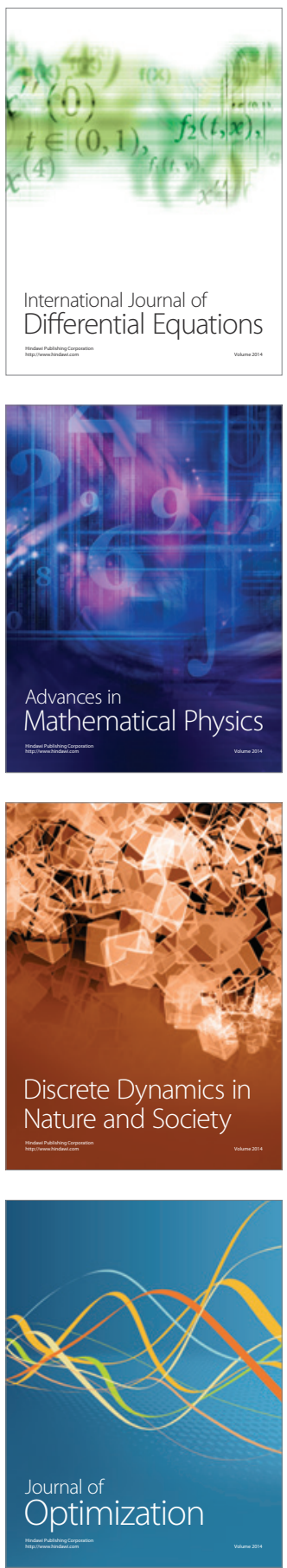